\title{
Late onset obesity in mice with targeted deletion of potassium inward rectifier Kir7.1 from cells expressing the melanocortin-4 receptor
}

\author{
Erica J. P. Anderson ${ }^{1}$ | Masoud Ghamari-Langroudi ${ }^{1}$ | Isin Cakir ${ }^{1,2}$ | Michael J. Litt ${ }^{1}$ | \\ Valerie Chen $^{3}$ | Roman E. Reggiardo ${ }^{3}$ | Glenn L. Millhauser ${ }^{3}$ | Roger D. Cone ${ }^{1,2,4}$ (i)
}

${ }^{1}$ Department of Molecular Physiology and Biophysics, Vanderbilt University, Nashville, Tennessee

${ }^{2}$ Life Sciences Institute, University of Michigan, Ann Arbor, Michigan

${ }^{3}$ Department of Chemistry and Biochemistry, University of California Santa Cruz, Santa Cruz, California

${ }^{4}$ Department of Molecular and Integrative Physiology, School of Medicine, University of Michigan, Ann Arbor, Michigan

\section{Correspondence}

Roger D. Cone, Life Sciences Institute, University of Michigan, Ann Arbor, MI.

Email: rcone@umich.edu

Funding information

National Institute of General Medical Sciences, Grant/Award Number: T32 GM007347 (MJL); National Institute of Diabetes and Digestive and Kidney Diseases, Grant/Award Number: F30DK108476 (MJL), RO1DK070332 (RDC), RO1DK110403 (GLM) and T32DK07563 (EJPA); Pfizer, Inc. (RDC).
Energy stores in fat tissue are determined in part by the activity of hypothalamic neurones expressing the melanocortin- 4 receptor (MC4R). Even a partial reduction in MC4R expression levels in mice, rats or humans produces hyperphagia and morbid obesity. Thus, it is of great interest to understand the molecular basis of neuromodulation by the MC4R. The MC4R is a G protein-coupled receptor that signals efficiently through $G \alpha_{S}$, and this signalling pathway is essential for normal MC4R function in vivo. However, previous data from hypothalamic slice preparations indicated that activation of the MC4R depolarised neurones via G protein-independent regulation of the ion channel Kir7.1. In the present study, we show that deletion of Kcnj13 (ie, the gene encoding Kir7.1) specifically from MC4R neurones produced resistance to melanocortin peptide-induced depolarisation of MC4R paraventricular nucleus neurones in brain slices, resistance to the sustained anorexic effect of exogenously administered melanocortin peptides, late onset obesity, increased linear growth and glucose intolerance. Some MC4R-mediated phenotypes appeared intact, including Agoutirelated peptide-induced stimulation of food intake and MC4R-mediated induction of peptide $Y Y$ release from intestinal $L$ cells. Thus, a subset of the consequences of MC4R signalling in vivo appears to be dependent on expression of the Kir7.1 channel in MC4R cells.

\section{KEYWORDS}

Kcnj13, Kir7.1, MC4R, melanocortin-4 receptor, obesity

\section{1 | INTRODUCTION}

Haploinsufficiency of the melanocortin-4 receptor (MC4R) in humans is the most common monogenic cause of severe obesity, accounting for up to $5 \%$ of cases. ${ }^{1,2}$ The composite prevalence of obesity-causing deleterious alleles in the human population has been demonstrated to be approximately 1 in $1500,{ }^{3}$ and a detailed clinical picture of the syndrome has been reported. ${ }^{4,5}$ Remarkably, the syndrome is virtually identical to that reported for the mouse $e^{6-8}$ with increased adipose mass, lean mass, linear growth, hyperinsulinaemia and severe hyperphagia. Genome-wide association studies have also identified single nucleotide polymorphims adjacent to the MC4R gene that are associated with obesity. ${ }^{9-11}$ These noncoding changes also support the notion that small changes in the expression level or activity of the MC4R may impact adiposity. Humans with haploinsufficiency, or even homozygous null status at the MC4R, are 
relatively normal outside of the obesity syndrome, with only mild hypotension and hyperinsulinaemia being reported. Another unique feature of the central melanocortin system are the gene dosage effects for $M C 4 R,{ }^{8,12}$ a highly unusual finding for $G$ protein-coupled receptor signalling systems.

Thus, the MC4R is a well-validated target for the treatment of common obesity ${ }^{8,9}$ and cachexia. ${ }^{13-16}$ Other studies suggest potential applications in diabetes ${ }^{7,17,18}$ and the metabolic syndrome, ${ }^{19,20}$ depression-related anorexia and anhedonia, ${ }^{21}$ and obsessive-compulsive disorder. ${ }^{22}$ The MC4R appears to be at the heart of the adipostat, in that administration of melanocortin agonists inhibits food intake ${ }^{12}$ and increases energy expenditure. ${ }^{23}$ Chronic administration of potent melanocortin agonists produces significant weight loss in model systems, from rodents to primates. ${ }^{24}$ However, clinical trials of potent small molecule orthosteric agonists of the MC4R have failed as a result of target-mediated pressor effects. Despite the target-mediated pressor response resulting from most melanocortin agonists, two peptide analogues of the native MC4R ligand, $\alpha$-melanocyte-stimulating hormone $(\alpha-M S H)$, have been demonstrated to cause weight loss without a pressor response. ${ }^{24-27}$ One of these compounds, setmelanotide, has been used successfully in a clinical trial in two patients with compound heterozygous mutations in pro-opiomelanocortin (POMC), the preprohormone precursor for $\alpha-\mathrm{MSH}^{24}$ and in a clinical trial in patients with homozygous mutations in the gene encoding the leptin receptor. ${ }^{28}$ There are no data available explaining why some MC4R agonists are capable of inducing weight loss without the target-mediated pressor response, although biased agonism must be considered in the event that multiple signalling pathways are activated downstream of MC4R.

In this regard, it is already appreciated that MC4R exhibits different signalling modalities on the cellular level in vivo. The MC4R couples to $G \alpha_{S}$ in all cells tested, and it has been demonstrated that deletion of $\mathrm{G} \alpha_{S}$ from MC4R neurones recapitulates the phenotype seen in MC4R knockout mice. ${ }^{29}$ However, the complexity of MC4R signalling in vivo is also clear. $\alpha-\mathrm{MSH}$ activates MC4R positive intermediolateral nucleus neurones via a putative nonspecific cation channel, ${ }^{30}$ whereas it inhibits MC4R neurones in the dorsal motor nucleus of the vagus nerve via activation of a $\mathrm{K}_{\text {ATP }}$ channel. ${ }^{31}$ Recently, using a hypothalamic slice preparation in the mouse, we demonstrated that $\alpha-\mathrm{MSH}$ appears to depolarise and activate MC4R neurones in the paraventricular nucleus (PVN) via a G protein-independent mechanism involving inhibition of the inward rectifier channel Kir7.1. ${ }^{32}$ This is a highly unusual finding, requiring further validation in vivo. Furthermore, a better understanding of the role(s) of variant MC4R signalling modalities in vivo might lead to a rationale pharmacological approach for the development of small molecule biased agonists of MC4R that could discriminate between weight loss and pressor activities. Aiming toward these two goals, we specifically deleted the inward rectifier Kir7.1 from MC4R cells in the mouse and conducted pharmacological and physiological studies on the resulting animals.

\section{2 | MATERIALS AND METHODS}

\subsection{Mouse strains and genotyping}

We used promoter-driven, knockout-first, Kcnj13 targeted selection clones from the Knock-Out Mouse Project (KOMP) Repository at UC Davis (Davis, CA, USA) for the generation of transgenic mice. Embryonic stem cell clones expressing the mutant allele Kcnj13 $3^{\text {tm1a(KOMP)wtsi }}$ were expanded at Vanderbilt's Transgenic Mouse/ES Cell Shared Resource (TMESCSR, Nashville, TN, USA), where chimeric mice were generated on the $\mathrm{C} 57 \mathrm{BL} / 6 \mathrm{~N}$ background. Germ line transmission was confirmed by crossing chimeric male mice to wild-type C57BL/6N females. Genotyping confirmed the presence of the mutant allele, Kcnj13 ${ }^{\text {tm1a(KOMP)wtsi }}$, in progeny. This allele also carries an En2 splice acceptor sequence and a poly-A transcription termination signal, which disrupts Kcnj13 gene function. Following the KOMP breeding strategy for mutant allele generation, Kcnj13 $3^{\text {tm1a(KOMP)wtsi }}$ mice were bred to mice expressing the recombinase flippase to generate the $K c n j 13^{\operatorname{tm} 1 c(K O M P) w t s i}$ allele. The expression of flippase recombinase excised the promoter-driven Neo cassette, converting allele tm1a into conditional mutant allele tm1c. Mutant Kcnj13 $3^{\text {tm1c(KOMP)wtsi }}$ mice were mated to sibling mice to build a colony of Kcnj1 $3^{\text {tm1c }}$ mice (referred to as Kcnj13 ${ }^{\mathrm{fl} / \mathrm{fl}}$ mice). The Kcnj13 ${ }^{\mathrm{fl} / \mathrm{fl}}$ colony was crossed with a MC4R-t2A-Cre Tg/+ line (kindly provided by Dr Bradford Lowell, Beth Israel Deaconess Medical Center, Boston, MA) to generate a MC4R cell-specific Kcnj13 knockout experimental animal (referred to as $K c n j 13 \Delta M C 4 R^{C r e}$ ). This allele is referred to as Kcnj13 $3^{\text {tm1d }}$ in KOMP nomenclature. All mouse lines were maintained on a $\mathrm{C} 57 \mathrm{BL} / 6 \mathrm{NJ}$ background with annual backcrosses to wild-type C57BL/6NJ mice (Jax Stock No. 005304; Jackson Laboratory; Sacramento, CA, USA).

Mc4r-tau-Sapphire mice for electrophysiological studies were obtained from the Jackson Laboratory (Jax Stock No. 008323).

Primers for genotyping $\mathrm{Kcnj1} 13^{\mathrm{fl} / \mathrm{fl}}$ or $\mathrm{Kcnj13^{+/+ }}$ alleles were: Kcnj13_ttR CCAGAGGGTGAGGCTTATAATTTGTGC and Kcnj13_F GGTCAGTGAGATATGGCCTAGTGGG.

\section{2 | Mouse handling}

All mice were housed under standard, infection-free housing conditions under a $12: 12$ hour dark cycle at $25^{\circ} \mathrm{C}$. The strictly pathogenfree quality of the mouse colonies was maintained through quarterly serology, quarterly histopathologic examinations, as well as daily veterinarian monitoring of the general health and welfare of animals. Male and female mice were used for these experimental procedures. Mice were weaned at 4 weeks of age and maintained with four or five mice per cage, unless the animals were used for feeding studies. Animals used in feeding analysis were singly housed for acute studies and dually housed for long-term feeding studies. Unless otherwise described, all mice were fed a standard chow diet (Lab Diet; Purina, St Louis, MO, USA; S-5LOD: 13.5 kcal\% fat, 32.98 kcal\% protein, $56.7 \mathrm{kcal} \%$ carbohydrate). Diet-induced obesity was promoted by a high-fat diet (HFD) (Research Diets, New Brunswick, 
NJ, USA; D12492: 60 kcal\% fat, 20 kcal\% protein, 20 kcal\% carbohydrate). Post-mortem studies were conducted by giving animals a dose of $5 \mathrm{mg} \mathrm{kg}^{-1}$ tribromoethanol to deeply anaesthetise the mice before being killed via decapitation. Tissues of interest were rapidly excised and flash frozen by liquid nitrogen. All procedures were carried out with approval from the Institutional Animal Care and Use Committee of Vanderbilt University Medical Center.

\section{3 | Hypothalamic slice electrophysiology}

Mc4r-tau-Sapphire mice, backcrossed onto the C57BL/6J background, were previously characterised by dual immunohistochemistry and in situ hybridisation to confirm that green fluorescent protein (GFP)-positive neurones in the PVN expressed MC4R RNA. ${ }^{33}$ Randomly selected MC4R-GFP male and female mice in the Kcnj13 $\triangle M C 4 R^{\text {Cre }}$ or $K c n j 13^{+/+} ; M C 4 R^{\text {Cre }}$ background, 8-16 weeks of age, were deeply anaesthetised with isoflurane before decapitation. The brain was entirely removed and immediately submerged in icecold, gassed $\left(95 \% \mathrm{O}_{2}, 5 \% \mathrm{CO}_{2}\right)$ artificial cerebrospinal fluid (aCSF), containing (in mmol L-1): $126.2 \mathrm{NaCl}, 3.1 \mathrm{KCl}, 2 \mathrm{CaCl}_{2}, 1 \mathrm{MgCl}_{2}$, $1 \mathrm{NaH}_{2} \mathrm{PO}_{4}, 26.2 \mathrm{NaHCO}_{3}, 10$ glucose and 11 sucrose (320 mosm kg ${ }^{-1}$, $\mathrm{pH} 7.39$ when gassed with $95 \% \mathrm{O}_{2}, 5 \% \mathrm{CO}_{2}$ at room temperature). Brain blocks containing hypothalamus were made by trimming whole brains when the brains were immersed in oxygenated, near-freezing aCSF and glued to a dental-cement cast customised to the size of the block mounted on a plate with adjustable angle. Brain slices of $200 \mu \mathrm{m}$ in thicknesses were then cut at an angle range between $44^{\circ}$ and $49^{\circ}$ in reference to the horizontal plane and transferred to a glass beaker containing oxygenated $\mathrm{aCSF}$ at $31^{\circ} \mathrm{C}$. After an incubation period lasting at least 1 hour, a slice was transferred to a recording chamber (approximately $2.0 \mathrm{~mL}$ in volume), then submerged and immobilised with nylon strands drawn taut across a C-shaped platinum wire (outer diameter $1 \mathrm{~mm}$ ) and perfused with warmed $\left(31-32^{\circ} \mathrm{C}\right)$ oxygenated aCSF at a rate of 2-3 $\mathrm{mL} \mathrm{min}^{-1}$. Enhanced GFP-fluorescent neurones were unambiguously identified and patched using combined epifluorescence and infrared-differential interference contrast (IR-DIC) optics. Fluorescent neurones of healthy IR-DIC appearance but of every level of fluorescence brightness were chosen for electrophysiological recordings. Drugs were added to aCSF and bath applied to the slice via the perfusion system for extracellular application. The small volume of the recording chamber relative to the flow rate assured a complete exchange of solution occurring in less than 1 minute. The persisting effects of a peptide were therefore a result of prolonged effects rather than a slow wash out.

In the present study, whole-cell patch-clamp recordings were used to obtain information about action potential firing activity, as well as membrane potentials and currents. Unless stated otherwise, whole-cell recordings were performed using patch pipettes of 3.4 $\mathrm{M} \Omega$ to $5 \mathrm{M} \Omega$ resistance when filled with a solution containing (in mmol L-1); $125 \mathrm{~K}$ gluconate, $8 \mathrm{KCl}, 4 \mathrm{MgCl}_{2}, 10$ Hepes, $5 \mathrm{NaOH}$, $4 \mathrm{Na}_{2}$ ATP, $0.4 \mathrm{Na}_{3}$ GTP, $5 \mathrm{Na}_{2}$-creatine phosphate, 7 sucrose and 7 $\mathrm{KOH}$, which resulted in a approximate $\mathrm{pH} 7.23$ and osmolality of 295-300 mosmol kg${ }^{-1}$. The permeability of the $\alpha-\mathrm{MSH}$ regulated channels was investigated by replacing $\mathrm{K}$ gluconate and $\mathrm{KCl}$ with 130 $\mathrm{RbCl}$ and $4 \mathrm{KCl}$, but otherwise similar conditions. The examination of effects of $\mathrm{Mg}^{2+}$-free internal solution on the $\alpha-\mathrm{MSH}$-induced current was conducted in voltage-clamp mode from PVN neurones held at $-55 \mathrm{mV}$. The $\mathrm{Mg}^{2+}$-free internal solution contained (in mmol $\mathrm{L}^{-1}$ ) $103 \mathrm{~K}$ gluconate, $30 \mathrm{KCl}, 10 \mathrm{Hepes}-\mathrm{KOH}, 0.5 \mathrm{CaCl}_{2}$ and $5.5 \mathrm{EDTA}$ $\mathrm{KOH}\left(\mathrm{pH}\right.$ 7.23), with osmolality $304 \mathrm{mosmol} \mathrm{kg}^{-1}$. The ATP free

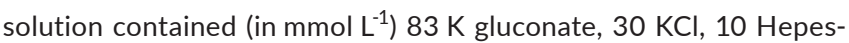
$\mathrm{KOH}, 0.5 \mathrm{CaCl}_{2}, 4 \mathrm{MgCl}_{2}$ and $5.5 \mathrm{EGTA}-\mathrm{KOH}$ (pH 7.2), with osmolality 298 mosmol kg-1. Neuronal integrity was assessed by all of the following: small holding current ( $\leq 30 \mathrm{pA}$ at $-70 \mathrm{mV}$ ) when voltageclamped, large amplitude rebound spikes, the ability to fire and a lack of obvious morphological deterioration (ie, lack of blebbing and nucleus not visually present).

To quantify the action potential firing and amplitude of depolarisation induced by $\alpha-\mathrm{MSH}$, current-clamp recordings were performed in continuous mode when the membrane potential of neurones was held between -55 and $-60 \mathrm{mV}$ to prevent continuous spontaneous action potential firing. The firing frequency and membrane potential of neurones was measured during a 3-minute period before the application of the peptides, and for another 3-minute period 7-11 minutes after administration of peptide, with the results being compared.

Data were acquired at $10 \mathrm{kHz}$ using a MultiClamp 700A amplifier (2000x gain, $-3 \mathrm{~dB}$ filter frequency $5 \mathrm{kHz}$ ) and CLAMPEX, version 10.0.1 (Axon Instruments, Union City, CA, USA). PRISM, version 5.0 (Graphpad Software, Inc., San Diego, CA, USA) and EXCEL 2010 (Microsoft Corp., Redmond, WA, USA) were used for data analysis. Statistical tests used included the paired $t$ test, when examining the response of the same neurones before and after treatment with a compound, and the unpaired $t$ test when comparing the responses of different sets of neurones.

\section{4 | Fast-induced refeeding}

Age and litter matched male and female mice were used for the present study as obtained from young (not shown) and mature (35-45 weeks of age) cohorts. Studies were repeated at least three times across multiple cohorts. One week before the study, mice were singly housed and accustomed to handling with i.p. injections of $100 \mu \mathrm{L}$ of saline when provided with $a b$ lib. standard chow and water. One day before the study, mice were moved to clean cages with fresh bedding to minimise coprophagia. Mice were food deprived for 16-24 hours before the drug was administered at the beginning of the dark cycle.

Experiments were blinded; drug compounds were prepared and coded on the morning of the injections by an individual who would not be conducting the experiment. The randomly selected experimental groups consisted of animals that were given vehicle (saline) or $10.0 \mathrm{mg} \mathrm{kg}^{-1}$ of the melanocortin agonist LY2112688 (LY). For repeated studies, animals rested at least 7 days between fasting periods and opposite treatments were given. The numbers needed to achieve significant inhibition of food intake by a melanocortin compound versus 
saline were based on prior experience. Food intake was measured at multiple time points after injection, beginning at 2 hours and extending as far as 40 hours after injection. In viral knockdown studies, a ground feeding canister with a wire mesh bottom was used, rather than the cage hopper. Mice were accustomed to the presence of the canister in their cage for 1 week before the experiment. The reduced accessibility of this apparatus is reflected by the reduced chow consumption in viral knockdown mice compared to cell-specific genetic deletion mice studies. Statistical significance was established using two-way ANOVA and Tukey's post-hoc test. $P<0.05$ was considered statistically significant.

\section{5 | Short hairpin RNA (shRNA) lentiviral design and hypothalamic injection}

Mouse Kcnj13 shRNA and scramble shRNA (sc shRNA) were constructed using the vector pSico (Addgene, Cambridge, MA, USA). Kcnj13 shRNA plasmid (TRCN0000262099) (clone \#99) (see Supporting information, FigureS3) was from Sigma(St Louis, MO,USA) with sequence: CCGGCGCCTTACTTGCCATACAAATCTCGAGAT TTGTATGGCAAGTAAGGCGTTTTTG. Scramble shRNA (plasmid\# 1864) was purchased from Addgene. Scramble shRNA construct in pLKO.1 vectors was subcloned into pLL3.7 (plasmid \#:11795; Addgene), which also encodes GFP. pLL3.7 plasmid with shRNA (scramble vs. Kcnj13). Kcnj13 shRNA sequence (see Supporting information, Figure S3) was cloned into pLKO.1 expressing mCherry.

293T cells were transfected with $12.6 \mu \mathrm{g}$ of plasmids containing the shRNA (scramble vs. Kcnj13) and $6.3 \mu \mathrm{g}$ each of the following plasmids: pRSV-Rev, pVSVG and pMDLp/g (gift from Dr Roger Colbran, Vanderbilt University School of Medicine, Nashville, TN) using Lipofectamine 2000 (Invitrogen, Carlsbad, CA, USA) on $15 \mathrm{~cm}$ dishes. Some 96 hours post-transfection, culture medium from five $15 \mathrm{~cm}$ plates per shRNA clone were collected, and filtered through a $0.45-\mu \mathrm{m}$ filter. Viral particles were isolated by ultracentrifugation at $4{ }^{\circ} \mathrm{C}$ and $76800 \mathrm{~g}$ for 2 hours. The pellet was resuspended in sterile phosphatebuffered saline, aliquoted and frozen at $-80^{\circ} \mathrm{C}$ until further use.

Viral titre was quantified as follows: 100000 293T cells were plated on 24-well plates. Cells were transduced by ten-fold serial dilutions of the viral particles with a dilution range between 1:10 and $1: 10^{5}$ using polybrene. GFP (for scramble shNA) or mCherry (for shRNA against Kcnj13) positive cells were counted in triplicate. Purified lentivirus suspended in $550-600 \mathrm{~nL}$ of aCSF was injected bilaterally and infused over 15 minutes into the PVN using a stereotactic frame and the coordinates of $0.82 \mathrm{~mm}$ posterior to bregma, $0.31 \mathrm{~mm}$ lateral to the midline of the brain and $4.68 \mathrm{~mm}$ below the surface of the skull, via a 26-gauge guide cannula and a 33-gauge internal injector (Plastics One, Roanoke, VA, USA) connected to a $2-\mu \mathrm{L}$ Hamilton syringe.

\subsection{Cannulation surgery for i.c.v. injection}

To investigate the effect of i.c.v. injection of $A g R P$, mice were anaesthetised with isoflurane and a stainless-steel cannula (Plastics One) was surgically implanted into the right lateral ventricle using the stereotaxic coordinates of $0.46 \mathrm{~mm}$ posterior to the bregma, $1.0 \mathrm{~mm}$ lateral to the midline and $2.2 \mathrm{~mm}$ below the surface of the skull. Mice were allowed to recover for approximately 5 days at the same time as monitoring food intake and body weight with acclimatisation to handling and manipulation of the dummy cannula. After recovery, cannula placement was verified by injecting $10 \mathrm{ng}$ of angiotensin II (Sigma) diluted in $0.5 \mu \mathrm{L}$ of sterile saline. Animals that did not exhibit a drinking response within 30 minutes were excluded from the study. One day later, experimental procedures were initiated during the light cycle. Peptides $\left(\mathrm{AgRP}_{83-132}\right)$ or vehicle were infused in a volume of $0.5 \mu \mathrm{L}$ over a 1-minute period with a 2.0- $\mu$ L Hamilton syringe (Plastics One) coupled to an injection cannula via polyethylene tubing. After injection, the injector was kept in place for 1 minute to ensure diffusion from the injector tip. Food intake and body weight was monitored after injection. When the experimental procedures concluded, cannula placement was also confirmed histologically.

\section{7 | Plasma hormone measurements}

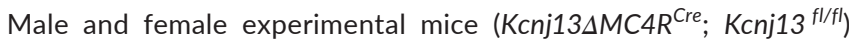
aged 25-27 weeks were acclimated to scruffing and injections for up to 5 days prior to blood collection. The day of the study, postprandial plasma peptide YY (PYY) was reduced to baseline levels by a 6-hour daytime fast. Mice were randomly selected to receive an i.p. injection of vehicle (saline) or $5 \mathrm{mg} \mathrm{kg}^{-1}$ LY2112688 in volumes of $100-200 \mu \mathrm{L}$ in accordance with body weight. Numbers were chosen based on prior experience suggesting that significance can be achieved with six animals per treatment. At 10 minutes post-injection, approximately $200 \mu \mathrm{L}$ of blood was collected via submandibular bleeding in conscious mice or by decapitation under anaesthesia for trunk bleeding. Blood was collected into vials containing appropriate volumes of EDTA and protease inhibitor cocktail for mammalian tissues (P8340; Sigma) to prevent degradation of PYY and kept on ice. Upon collection of all blood samples, the vials were spun at $3000 \mathrm{~g}$ for 30 minutes at $4^{\circ} \mathrm{C}$. Plasma was removed and spun at $10000 \mathrm{~g}$ for 1 minute at $4^{\circ} \mathrm{C}$ to pellet remaining blood cells. Plasma was frozen at $-80^{\circ} \mathrm{C}$ until PYY was assayed. Plasma hormones were assayed in 10- $\mu \mathrm{L}$ duplicate samples using the MilliplexMAP Mouse Metabolic Hormone Magnetic Bead Panel Immunoassay (MMHMAG-44K 1plex kit for total PYY; Merck, Darmstadt, Germany), with undiluted plasma to detect PYY (total). The assay was read on a Luminex 100 analyser (Luminex Corp., Austin, TX, USA). The results were analysed against a standard curve and concentrations were determined using MILLIPLEX ANALYST, version 5.1 (Merck). Values were plotted and analysed using PRISM (GraphPad Software Inc., San Diego, CA, USA). Statistical analyses were conducted using multiple $t$ tests.

\section{8 | Growth phenotyping}

Male and female mice were dually housed with same sex, same genotype animals of similar weight to collect weekly food intake (standard chow or diet-induced obesity [DIO]) and growth data. Mouse 
lean and fat mass body composition was obtained by NMR (mq10 Minispec; Bruker, Billericia, MA, USA).

\section{9 | Metabolic studies}

Glucose tolerance testing was conducted as described previously. ${ }^{34}$ Three days prior to the glucose tolerance test (GTT), the body composition was obtained to determine the lean body mass. Mice were then habituated to consecutive, daily handling sessions. On the study day, mice were fasted for 6 hours (from 9:00 AM to 3:00 PM). Mice were scruffed to obtain a basal glucose read by tail nick, then injected with 1 (DIO) to 2 (chow) $\mathrm{mg} \mathrm{kg}^{-1}$ lean mass dose of glucose in sterile phosphate-buffered saline. Tail vein bleeding was performed at 15, 30, 4560,90 and 120 minutes after the injections. Glucose readings were obtained by tail vein bleeds at the times indicated. Glucose was measured using Aviva PLUS Glucose test Strips (Roche Diagnostics). Lean mass was determined by a NMR body composition scan (mq10 Minispec; Bruker). Repeated sampling by tail vein bleeding was carried out at intervals at least 1 week apart to allow for a complete recovery from blood loss. The area under the curve was calculated using the trapezoidal rule.

\subsection{0 | Statistical analysis}

Sample size for growth curve studies was chosen using the power equation ( $\alpha<0.05, \beta=0.1, \Delta \mu=25 \% \sigma=5$ ), whereas sample sizes for the remaining studies were estimated based on previous publications. All statistical tests were conducted using PRISM, version 6 (Scientific Software, La Jolla, CA, USA). Data are presented as the mean \pm SE of the mean. $P<0.05$ was considered statistically significant. Experimental performers were generally blinded for the initial studies and partially blinded for genotype identity for the repeated studies. Experiments were repeated at least three times with age- and litter-matched animals across the experimental and control groups.

\section{RESULTS}

\section{1 | Global and tissue-specific deletion of Kcnj13}

To analyse the potential roles of Kir7.1 in MC4R neurones in vivo, we developed a versatile, transgenic mouse strategy (see Supporting information, Figure S1) using the KOMP mutant allele repository. After germ line transmission, the first generation mutant was a homozygous, global null mouse $\left(K c n j 13^{K O}\right)$. As previously reported using a Velocigene method, we confirmed that the $K c n j 13^{K O}$ resulted in early (P0) postnatal lethality (see Supporting information, Figure S2). ${ }^{35}$ Pathological analyses indicated retardation of lung and kidney development and failure to suckle as likely sources of lethality. We next derived a floxed line by crossing these animals with a flippase recombinase transgenic $\mathrm{C} 57 \mathrm{BI} / 6 \mathrm{NJ}$ line. Mice expressing Kcnj13 flanked by loxP sequences (Kcnj13 ${ }^{\mathrm{fl} / \mathrm{fl})}$ ) were confirmed by genotyping. Tissue-specific Kcnj13 knockout mice were then derived using the Cre-loxP method. Kcnj13 ${ }^{f / f l}$ mice were crossed with mice expressing the alleles $K c n j 13^{f l / f l}$ and MC4R-t2A-Cre Tg/+ $\left(M C 4 R^{C r e}\right)$ to generate a MC4R cell-specific Kcnj13 knockout experimental animal, hereafter referred to as $K c n j 13 \Delta M C 4 R^{\text {Cre }}$ (Table 1).

\section{2 | Defective $\alpha$-MSH-induced depolarisation of MC4R PVN neurones from Kcnj13 $M C 4 R^{C r e}$ mice}

Kcnj13 is expressed at low levels in the sparsely distributed MC4R neurones in the CNS. ${ }^{32}$ Thus, it is challenging to demonstrate tissuespecific deletion of Kcnj13 using mRNA expression. However, we had previously developed a functional assay of Kir7.1 in a hypothalamic slice preparation. ${ }^{32}$ In this assay, Kir7.1 was demonstrated pharmacologically to be required for $\alpha-\mathrm{MSH}$-induced depolarisation of MC4R neurones in the paraventricular nucleus of the hypothalamus. We chose to use this assay to test for Kir7.1 activity in MC4R neurones in $K c n j 13 \Delta M C 4 R^{C r e}$ mice. To characterise the necessity of Kir7.1 for $\alpha$-MSH-induced depolarisation of MC4R-expressing neurones within the PVN, electrophysiological slices were prepared from control

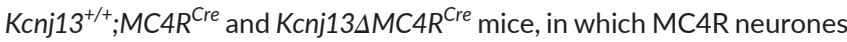
are transgenically labelled with GFP. Whereas a $250 \mathrm{nmol} \mathrm{L}^{-1}$ bath application of $\alpha$-MSH successfully depolarised PVN MC4R neurones in recordings from control mice (Figure $1 \mathrm{~A}$ ), depolarisation did not occur in recordings from PVN MC4R neurones from Kcnj13 $\triangle M C 4 R C$ re mice (Figure 1B). These data show the absence of a characterised Kir7.1 response in Kcnj13 $\triangle M C 4 R^{C r e}$ mice, thereby supporting the argument that Kir7.1 is not expressed in mutant Kcnj13 $\triangle M C 4 R^{C r e}$ PVN neurones, and that Kir7.1 is required for $\alpha-\mathrm{MSH}$-induced depolarisation in this electrophysiological slice assay. Figure 1(B) also shows representative traces from individual MC4R neurones in each genotype, as well as the membrane potential of MC4R neurones from each genotype, before and after $\alpha-\mathrm{MSH}$ treatment.

\subsection{Defective anorexic response to melanocortin peptides in Kcnj13 $\triangle M C 4 R^{\text {Cre }}$ mice}

Because the absence of Kir7.1 disrupted $\alpha-\mathrm{MSH}$-induced neuronal depolarisation in PVN MC4R neurones in an ex vivo slice
TABLE 1 Nomenclature of mouse strains used in the present study

\begin{tabular}{|c|c|c|}
\hline & Mouse Genome Informatics name & Common name \\
\hline Global knockout & C57BL/6J-Kcnj13 ${ }^{\text {tm1a(KOMP)Wtsi }}$ & Kcnj13 $3^{K O}$ \\
\hline Floxed allele & C57BL/6J-Kcnj13 $3^{\text {tm1c(KOMP)Wtsi }}$ & Kcnj13 ${ }^{f l / f l}$ \\
\hline Cell-specific knockout & C57BL/6J-Kcnj13 ${ }^{\text {tm1d(KOMP)Wtsi }}$ & Kcnj13 $\Delta M C 4 R^{\text {Cre }}$ \\
\hline Cre driver & Tg: C57BL/6J-MC4R-t2a-Cre & Kcnj13 $3^{+/+} ; M C 4 R^{C r e}$ \\
\hline
\end{tabular}




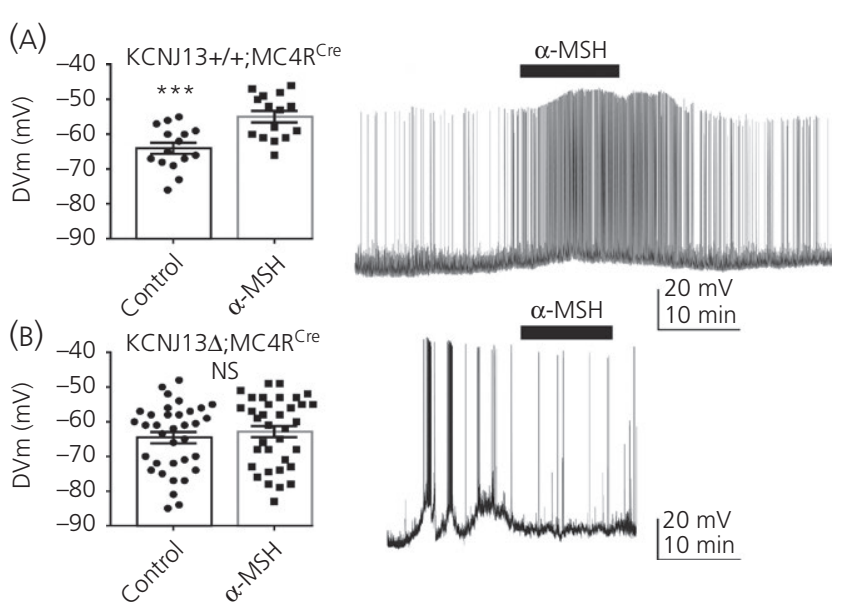

FIGURE 1 Defective $\alpha$-melanocyte-stimulating hormone ( $\alpha$ $\mathrm{MSH}$ )-induced depolarisation of melanocortin-4 receptor (MC4R) $P V N$ neurones in Kcnj13 $\triangle M C 4 R^{C r e}$ mice. Slice electrophysiology of PVN MC4R-GFP-positive neurones recorded in current clamp with bath application of $250 \mathrm{nmol} \mathrm{L} \mathrm{L}^{-1} \alpha-\mathrm{MSH}$. A, Recordings

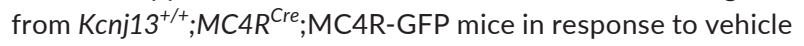
or $\alpha-\mathrm{MSH}$, showing that the induction of action potential differs significantly between and control and $\alpha-M S H$ in bath. A representative depolarising response of a PVN MC4R neurone is seen on the right. B, Recordings from Kcnj13 $\triangle M C 4 R^{C r e}$;MC4R-GFP mice show no significant response to $\alpha-M S H, P=0.11$. A representative response of a PVN MC4R neurone is seen on the right. Bar graph represents the mean \pm SEM of 15 -35 cells (*** $P<0.0001$, paired $t$ test). $\mathrm{DV}_{\mathrm{m}}$, membrane potential in millivolts $(\mathrm{mV})$. NS, not significant

preparation, we hypothesised that feeding behaviour in response to melanocortin agonist administration might also be adversely affected. To investigate the physiological effect of an MC4R agonist on MC4R neurones in the absence of Kir7.1 in vivo, we administered the potent $\alpha-\mathrm{MSH}$ analogue, LY2112688 (LY), at the beginning of the dark cycle, after a 16-24 hour fast, and measured food intake. Despite the powerful drive to restore energy stores resulting from a state of nutritional deficit, LY2112688 blunted the fasting-induced refeeding response in control genotype groups; however, in Kcnj13 $\triangle M C 4 R C r e$ male (Figure 2A) and female (Figure 2B) mice the duration of LY2112688 action was reduced. Notably, from 3 hours post refeeding in males and 4 hours post refeeding in females to 12 hours later, mice with MC4R specific deletion of Kir7.1 show a significantly reduced anorectic response to LY2112688 compared to $K c n j 13^{f l / f l}$ in males and $K c n j 13^{f l / f l}$ or $K c n j 13^{+/+} ; M C 4 R^{C r e}$ control groups in females. Additionally, at 13 and 24 hours, there was no significant difference between the action of saline or LY2112688 administered to $K c n j 13 \Delta M C 4 R^{C r e}$ males, whereas feeding in control Kcnj13 ${ }^{\mathrm{fl} / \mathrm{fl}}$ animals injected with LY2112688 remained suppressed.

The study paradigm was repeated using male mice following bilateral lentiviral Kcnj13 shRNA knockdown, or administration of a scrambled control lentivirus in the PVN (sc shRNA). Three different lentivirus constructs designed to knockdown Kcnj13 were purchased and tested for efficacy using HEK293 cells expressing Kcnj13 (see Supporting information, Figure S3). A virus yielding $>70 \%$ reduction in Kcnj13 mRNA levels (clone \#99) was selected for these experiments. After 3 weeks of recovery, mice were acclimated to handling and injection before beginning the fast-induced refeeding study (Figure $2 \mathrm{C}$ ). Similar to genetic deletion of Kir7.1, viral knockdown of Kir7.1 exclusively in the PVN also reduced the duration of the anorectic activity of LY2112688. LY2112688 was no longer effective at reducing food intake compared to saline in Kir7.1 knockdown animals from 12 hours post refeeding up to 40 hours. Conversely, LY2112688 significantly reduced chow consumption in mice with intact Kir7.1 for the duration of the study. Successful targeting and delivery of Kcnj13 shRNA or sc shRNA lentiviral vectors were confirmed by GFP expression localised to the PVN in post-mortem mice (not shown). Taken together, these data show that Kir7.1 expression was required for the extended duration of anorectic response to a melanocortin peptide.

We have previously shown the role of Kir7.1 in mediating a $G$ protein-independent MC4R response in both hypothalamic slices and in cells transfected with MC4R and Kir7.1. ${ }^{32}$ These electrophysiological and pharmacological experiments also demonstrated that AgRP appeared to open Kir7.1 channels in a MC4R-dependent manner. ${ }^{32}$ To determine whether Kir7.1 is necessary for AgRP-induced stimulation of food intake, we delivered i.c.v. AgRP to mice in a fed state. Cannulas were implanted in the lateral ventricle of $K c n j 13^{\mathrm{fl} / f \mathrm{ll}} \mathrm{Kcnj1} 13^{+/+} ; \mathrm{MC} 4 \mathrm{R}^{\mathrm{Cre} \text {, and }}$ $K c n j 13 \Delta M C 4 R^{C r e}$ male mice, and animals were allowed to recover for 5 days. Two days after a saline injection to establish baseline conditions, $2 \mathrm{nmol}$ of the peptide AgRP was injected i.c.v. during the light cycle. We observed no significant difference in central AgRP-induced feeding initiation or duration between genotypes (see Supporting information, Figure S4A), suggesting that Kir7.1 was not required for the orexigenic response to AgRP. Likewise, all genotypes responded to AgRP with an increase in body weight in proportion to the increase in food intake (see Supporting information, Figure S4B). There was no significant difference in change in body weight between genotypes.

\subsection{Normal melanocortin-stimulated PYY release in Kcnj13 $\triangle M C 4 R^{C r e}$ mice}

Although MC4R is expressed in many brain nuclei, peripheral expression has also been mapped. Notably, MC4R is expressed in enteroendocrine $L$ cells, and peripheral administration of $\alpha-\mathrm{MSH}$ has been demonstrated to induce MC4R-dependent release of PYY and GLP1 from these cells. ${ }^{36}$ Thus, the function of MC4R on $L$ cells can be assessed using an assay for increased plasma PYY following peripheral administration of an MC4R agonist. We next examined the requirement for Kir7.1 in MC4R-mediated PYY release from $L$ cells. The absence of Kir7.1 in MC4R cells did not interfere with the release of the satiety factor PYY into plasma (Figure 3). Thus, the role of Kir7.1 in MC4R function appeared to be important in neurones of the PVN but not enteroendocrine $L$ cells. 
FIGURE 2 Defective anorexic response to melanocortin agonist LY2112688 in Kcnj13 $\Delta M C 4 R^{\text {Cre }}$ mice. Feeding response in dark cycle after i.p. injection of saline or LY2112688 in male (A), or female (B) Kcnj13 $\triangle M C 4 R^{\text {Cre, }}$ Kcnj13 ${ }^{\mathrm{fl} / \mathrm{fl}}$ and/or Kcnj13 $3^{+/+}$;MC4R ${ }^{\mathrm{Cre}}$, $K_{c n j 13^{+/+}}$MC $4 R^{+/+}$and male (C) Kcnj13 shRNA or scamble short hairpin RNA lentiviral knockdown mice following a 16-24-h fast. LY2112688 was administered at $10 \mathrm{mg} \mathrm{kg}^{-1}$ ( $\mathrm{n}=4-9$ per group, ${ }^{*} P<0.05,{ }^{* *} P<0.005$, ${ }^{* * * *} P<0.0001$, two-way ANOVA with multiple comparisons test). NS, not significant
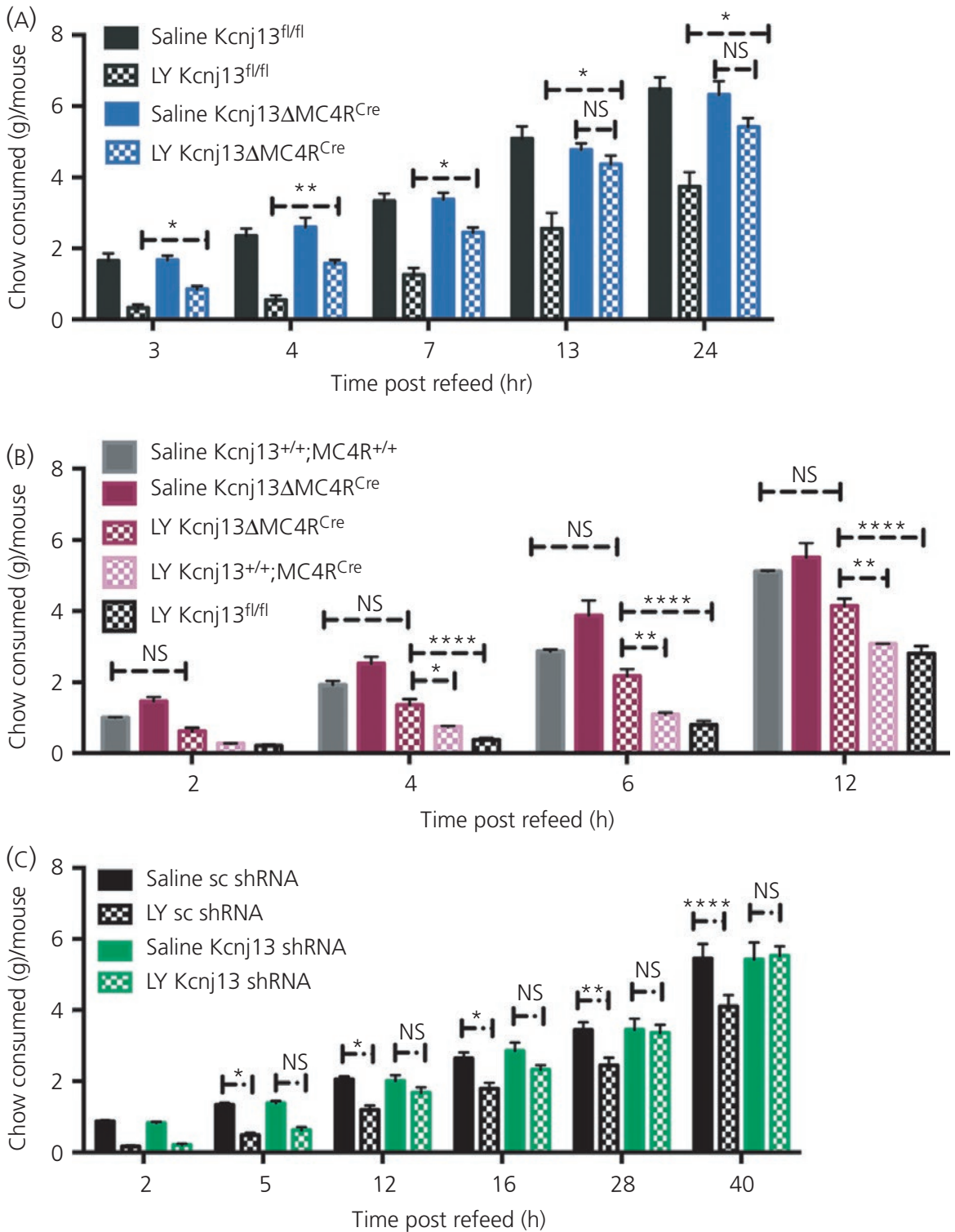

\subsection{Phenotypic characterisation of Kcnj13 $\triangle M C 4 R^{\text {Cre }}$ mice}

Global deletion of MC4R in the mouse can produce measurable increases in adipose mass as early as 5 weeks of age. ${ }^{8}$ To determine the effects of Kir7.1 ablation on MC4R signalling, we investigated body weight, body composition, feeding behaviour and glucose tolerance in Kcnj13 $\triangle M C 4 R^{C r e}$ and control Kcnj13 ${ }^{\mathrm{fl} / \mathrm{fl}}$,

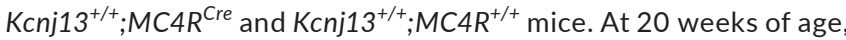
we did not observe differences in body weight in the four strains maintained on normal mouse chow (Figure 4A,B). Moreover, when lean and fat mass accrual are compared in young 12 week old mice and mature mice, no significant difference was detected in lean or fat mass between groups (Figure 4D-G). However, by 26 weeks of age in female mice and 50 weeks of age in male mice, Kcnj13 M MC4RCre animals show significantly greater weight compared to all three control strains (Figure 4A,B). One-way ANOVA showed that Kcnj13 $\triangle M C 4 R C r e$ male and female mice gained

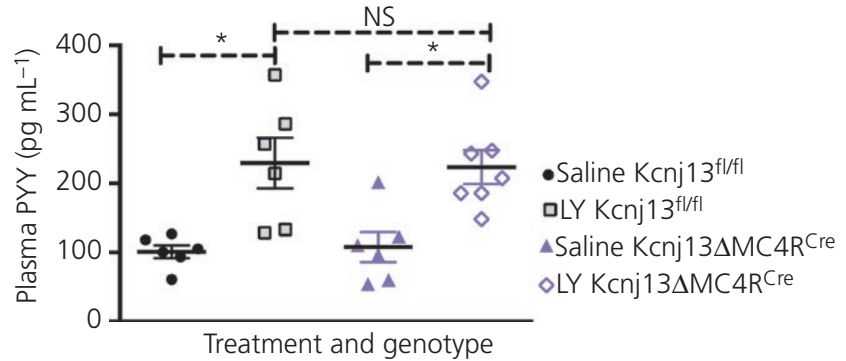

FIGURE 3 Normal melanocortin-stimulated plasma peptide $Y Y$ (PYY) release in Kcnj13 $\triangle M C 4 R^{\text {Cre }}$ mice. Male and female C57BL/6J $K c n j 13 \Delta M C 4 R^{C r e}$ and $K c n j 13^{f / f l}$ control mice were administered saline or saline containing $5 \mathrm{mg} \mathrm{kg}^{-1}$ LY2112688 i.p. Fifteen minutes following treatment, blood was collected and plasma was prepared. Plasma was then assayed for PYY using an enzymelinked immunosorbent assay (Luminex). Points indicate mean PYY concentrations determined in duplicate from individual mouse serum samples; bars indicate means from multiple mice $(n=6-7$ per group, ${ }^{*} P<0.05$, Student's $t$ test) 

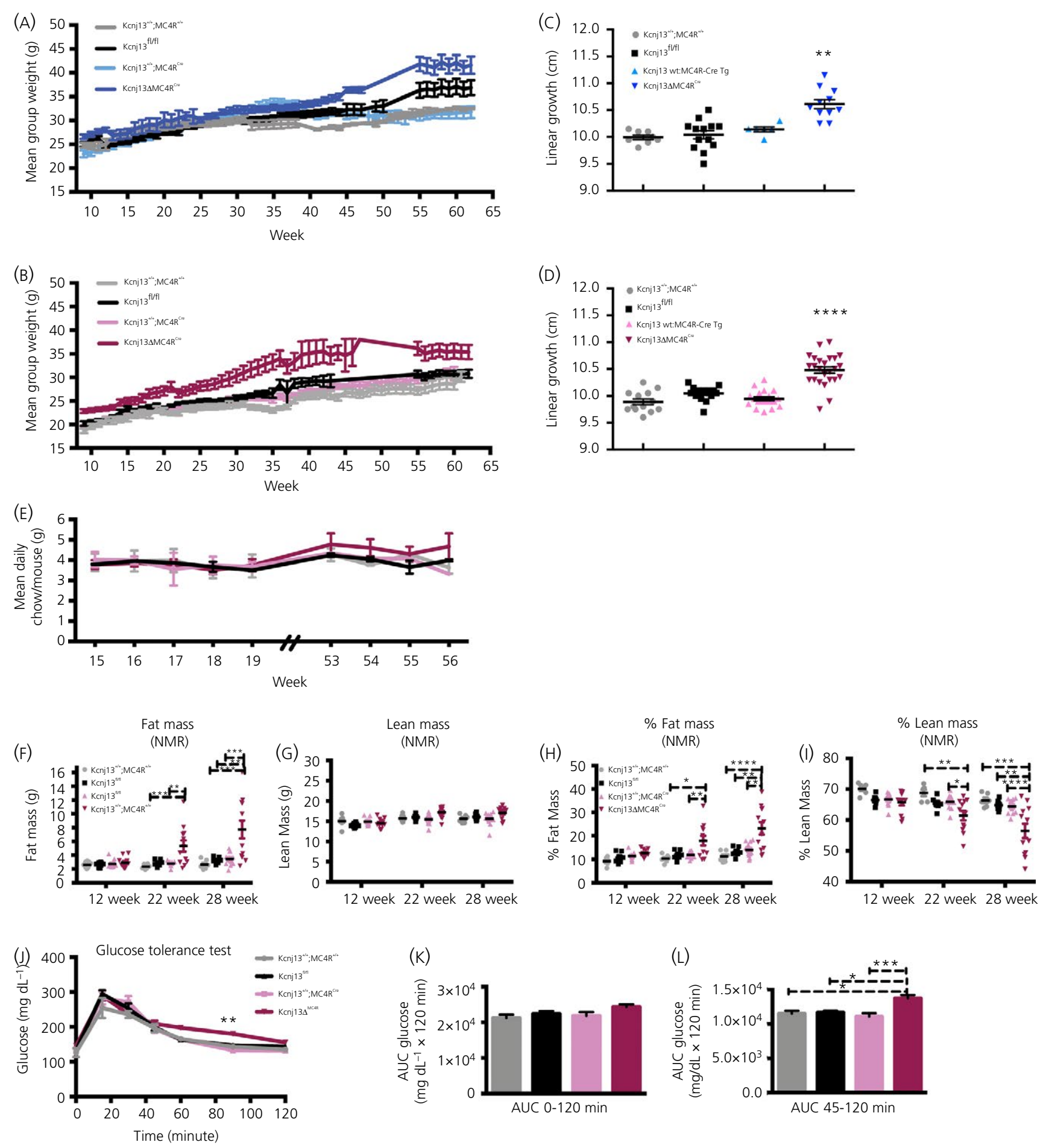

FIGURE 4 Late onset obesity develops in chow fed Kcnj13 $\Delta M C 4 R^{\text {Cre }}$ mice. Growth curves on chow diet of (A) male and (B) female mice interspersed across three age cohorts from 9 to 63 weeks. One-way ANOVA shows Kcnj13 $\Delta M C 4 R C r e$ male and female mice gained significantly more weight over the time course than the control genotypes. C, D, Snout-to anus length of euthanised female (C) and male

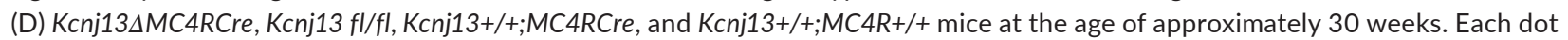
represents the snout-anus distance of one individual animal $\left(n=6-25\right.$ per group, ${ }^{* *} P<0.005,{ }^{* * * *} P<0.0001$, multiple $t$ test with HolmSidak post-hoc test). E, Daily chow consumption per mouse at mouse age indicated in weeks. One-way ANOVA test with Tukey's multiple comparisons. Absolute fat (F) and lean (G) mass and \%fat (H) and \%lean (I) mass body composition of 12-, 22- and 28-week-old female mice. Multiple $t$ tests with Holms-Sidak multiple comparison test. (J-L) Plasma glucose concentration during i.p. glucose tolerance test (IPGTT). Glucose $\left(2 \mathrm{~g} \mathrm{~kg}^{-1}\right)$, normalised to \% lean body mass, was administered to each animal. IPGTT was performed after $6 \mathrm{~h}$ of daytime fasting in 28-week-old female animals. Comparison of the difference in total area under the curve (AUC) shows (K) AUC from 0 to 120 is similar, whereas Kcnj13 $\triangle M C 4 R^{C r e}$ mice differ significantly from control genotypes from (L) 45-120 min. J, multiple $t$ tests, (K-L) One-way ANOVA with multiple comparisons ( $\mathrm{n}=6-12$ per group, ${ }^{*} P<0.05,{ }^{* *} P<0.005,{ }^{* * *} P<0.0005,{ }^{* * * *} P<0.0001$ ) 


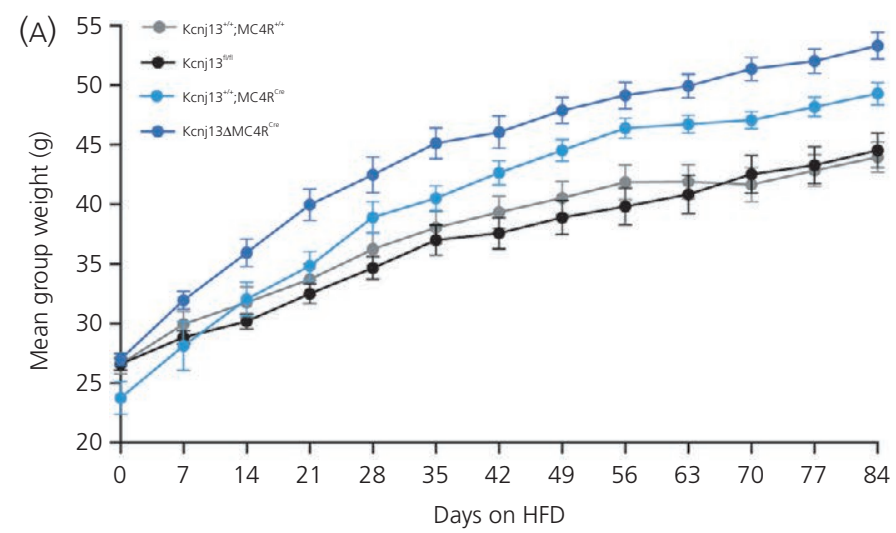

(B)
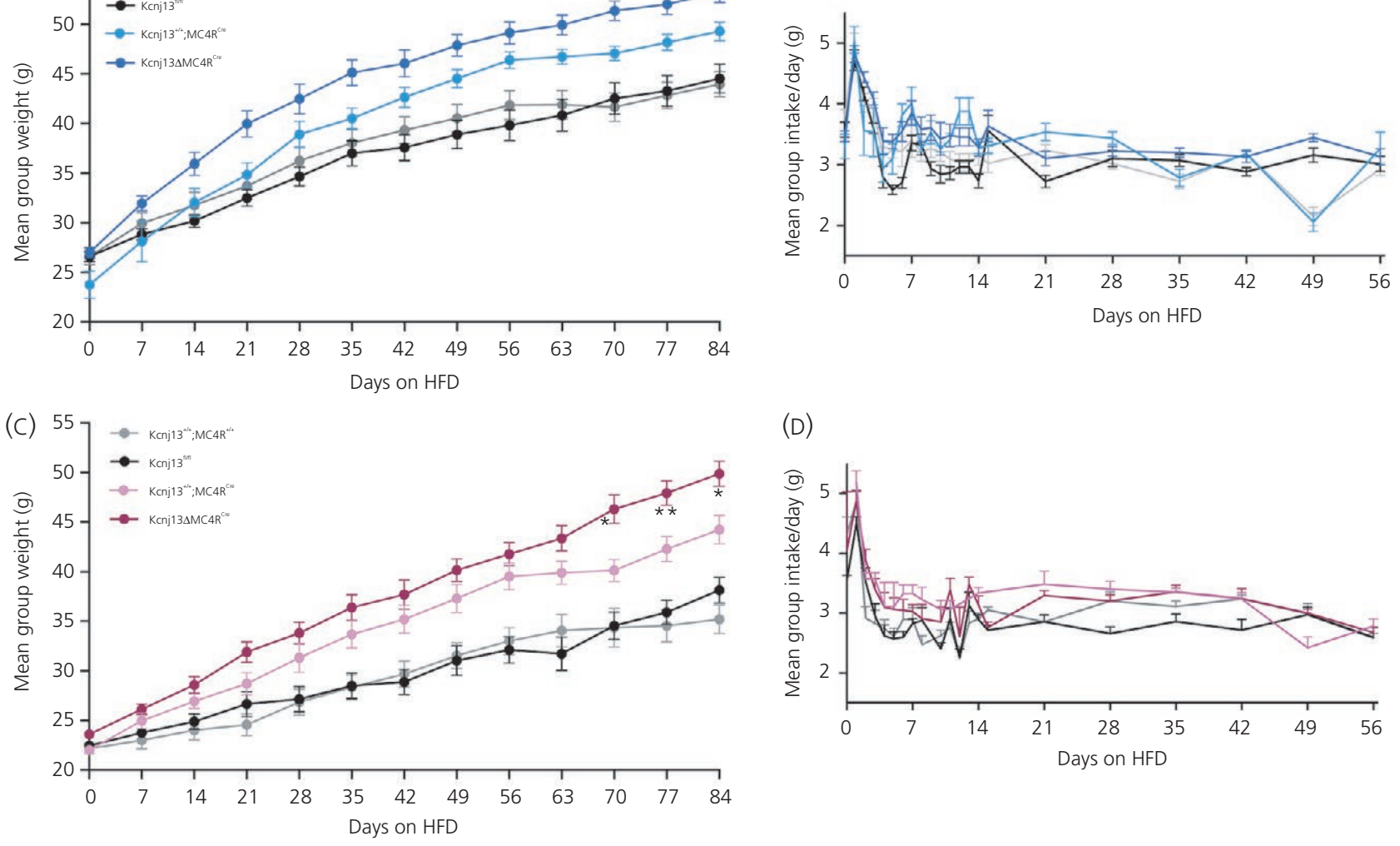

(D)
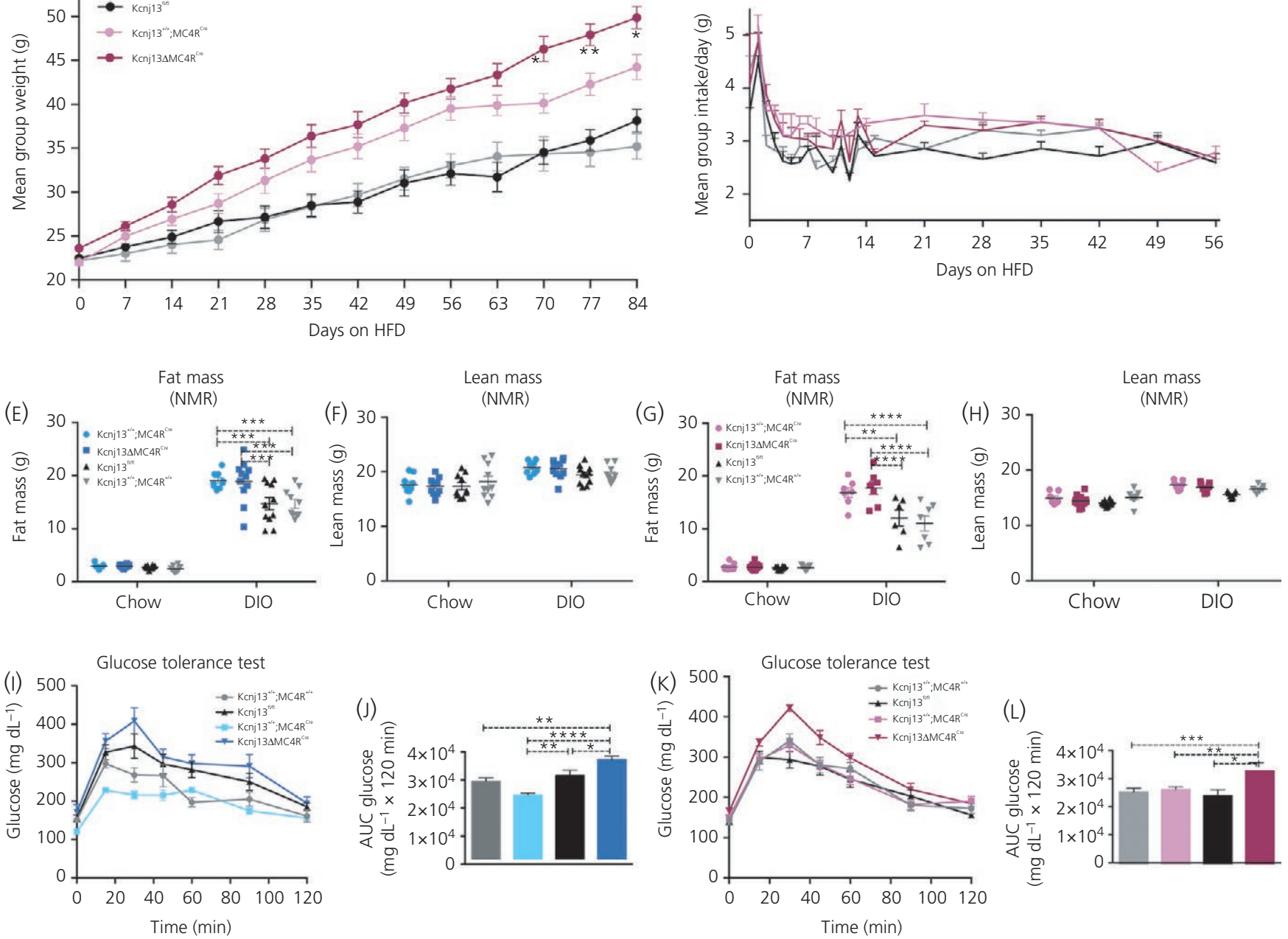

FIG URE 5 Obesity and glucose intolerance in Kcnj13 $\triangle M C 4 R^{\text {Cre }}$ mice on a high-fat diet (HFD). Growth curves on a HFD from (A) male and (C) female mice ( $\mathrm{n}=7-11$ per group, Mixed linear effect model of DIO male Kcnj13 ${ }^{+/+} ; M C 4 R^{\mathrm{Cre}}$ vs. Kcnj13 $3^{\mathrm{fl} / \mathrm{fl}} P<1.1 \times 10^{-6}$, female $P<2.2 \times 10^{-16} . K c n j 13^{+/+} ; M C 4 R C r e$ vs. Kcnj13 $\triangle M C 4 R^{C r e}$ male $P=0.01$, female $\left.P=0.8\right)\left({ }^{*} P<0.05,{ }^{* *} P<0.005\right.$ via multiple Students $t$ test

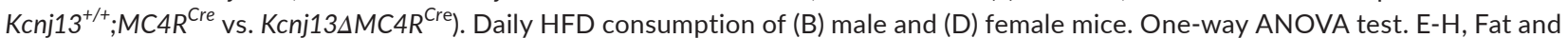
lean mass body composition of male (E-F) and female (G-H) on chow vs HFD. Two-way ANOVA with Tukey's multiple comparison test. (I-L) Plasma glucose concentration during i.p. glucose tolerance test (IPGTT). Glucose ( $\left.1 \mathrm{~g} \mathrm{~kg}^{-1}\right)$, normalised to \% lean body mass, was administered to each animal. IPGTT was performed after $8 \mathrm{~h}$ of daytime fasting in mice fed HFD for 5 months in (I) male and (K) female animals. Comparison of the percentage difference in total area under the curve (AUC) shows that Kcnj13 $\triangle M C 4 R^{C r e}$ differs significantly from control genotypes in $(\mathrm{J})$ males and (L) females ( $\mathrm{n}=6-8$ per group, ${ }^{*} P<0.05,{ }^{* *} P<0.005,{ }^{* * *} P<0.0005$, one-way ANOVA with Tukey's multiple comparisons test) 
significantly more weight over the time course than the control genotypes. No significant difference was observed in daily chow consumption between groups (Figure 4C). Using indirect calorimetry, no significant difference was observed in energy expenditure among the four strains (data not shown). At 28 weeks of age, female Kcnj13 $\triangle M C 4 R C r e$ mice weight were observed to have significantly more absolute and \%fat mass compared to control genotypes (Figure 4D,F), whereas lean mass was unchanged (Figure 4E). Both male and female 30 week old Kcnj13AMC4RCre animals also exhibited increased length relative to all controls (Figure 4C-D), as is observed in MC4RKO mice and humans. The \% lean mass (Figure 4G) was lower in Kcnj13 $\triangle \mathrm{MC} 4 \mathrm{RCre}$ mice as a result of the increase in adipose mass.

Glucose utilisation was assessed by an IP glucose tolerance test (GTT) in female mice at 28 weeks of age. The $2 \mathrm{mg} \mathrm{kg}^{-1}$ dosage of glucose was adjusted in proportion to lean body mass. Although all genotypes initially responded to the bolus of glucose similarly (Figure 4H,I), Kcnj13AMC4RCre mice showed impaired glucose metabolism from 45 to 120 minutes (Figure 4J). Impaired glucose disposal was also observed in experiments using lean 11-week-old female $K c n j 13 \Delta M C 4 R C r e$ mice, relative to control Kcnj13 ${ }^{\mathrm{fl} / f l}$ mice (data not shown).

To attempt to accentuate the physiological response to the deletion of Kir7.1 in MC4R cells, male and female animals of all four genotypes were placed on a HFD. Mice were acclimated to single housing at 8-10 weeks old and switched from chow to HFD at 10-13 weeks of age, during which time intake and growth were monitored weekly for 3 months. A clear obesogenic effect of the Cre transgene was apparent in genotypes with or without Kcnj13 under these conditions, perhaps as a result of a reduction of functional MC4R resulting from the method of Cre expression, requiring cleavage of an MC4R-Cre fusion protein expressed under the control of the endogenous MC4R promoter (see Supporting information, Figure S1). This method may result in the reduced expression of MC4R protein, and/ or a MC4R protein with reduced activity, as a result of the small t2A peptide fragment that remains at the end of the MC4R. Nonetheless, the increased weight of male and female Kcnj13 $\triangle M C 4 R^{C r e}$ mice was apparent compared to MC4R-Cre controls. A mixed linear effect statistical model, comprising an alternative to ANOVA with repeated measures, was used to analyse the growth curves. This modelling tool determined that the male Kcnj13 $\triangle M C 4 R C r e$ weight gain profiles (Figure 5A) are significantly greater than the Kcnj13+/+;MC4RCre controls. Female weight gain tended to be higher, and was also significantly different on HFD using Student's $t$ tests at individual time points from 70 to 84 days (Figure $5 \mathrm{C}$ ). We were unable to measure an effect of any genotype on food intake (Figure 5B,D). After consuming a HFD for 3 months, there is a significant increase in fat mass in both Kcnj13 $\triangle M C 4 R C r e$ and Kcnj13+/+;MC4RCre groups (Figure 5E-H); however, we were unable to measure an effect of Kir7.1 deletion, possibly as a result of the significant background effect of the Cre transgene (Figure 5E-H).

We next tested glucose utilisation by IPGTT. Glucose doses at $1 \mathrm{mg} \mathrm{kg}^{-1}$ were adjusted in proportion to lean mass. Despite the lack of a measurable difference in adipose mass between Kcnj13 $\triangle M C 4 R C r e$ and $K c n j 13+/+; M C 4 R C r e$ mice, male and female Kcnj13 $\Delta M C 4 R C r e$ mice have significantly reduced glucose tolerance compared to all control strains, including Kcnj13+/+;MC4RCre (Figure 5I-L).

\section{4 | DISCUSSION}

MC4R is known to signal through the G $\alpha$ s-cAMP signalling pathway in cell assays and in vivo. ${ }^{29,37}$ However, our data on MC4R signalling in a hypothalamic slice preparation from the mouse suggested that the MC4R depolarises neurones in the PVN via G protein-independent regulation of the inward rectifier Kir7.1. ${ }^{32}$ To assess the potential physiological role of this MC4R-Kir7.1 signalling pathway, we used Cre-loxP technology to delete Kir7.1 from MC4R-expressing cells in the mouse, and investigated the consequences on MC4R signalling, as well as on MC4R-mediated physiological responses.

Homozygous loss of Kir7.1 is known to cause degenerative eye diseases such as snowflake vitreoretinal degeneration and Leber congenital amaurosis ${ }^{38,39}$ in humans, and a pigmentary defect in the jaguar zebrafish, ${ }^{40}$ and thus we anticipated being able to conduct our studies in the global Kir7.1 knockout mouse. Surprisingly, however, we discovered that homozygous deletion of Kir7.1 in the mouse caused perinatal lethality. Histological analysis demonstrated stunted lung and kidney development, as well as reduced body mass (see Supporting information, Figure S2), and this same finding was reported by another laboratory. ${ }^{35}$ It is unclear why Kir7.1 is an essential developmental gene in the mouse but not zebrafish or humans, although the observation suggests variable physiological functions of this channel in different species.

After proceeding through a breeding strategy to obtain animals with a floxed Kcnj13 allele, we generated animals with MC4Rsite-specific deletion of Kir7.1. Because Kir7.1 is expressed at very low levels in the sparsely distributed MC4R neurones, ${ }^{32}$ we were unable to readily validate the absence of Kir7.1 mRNA from MC4R neurones. Recording from MC4R labelled cells in the PVN is a well-established tool for characterising MC4R firing activity. ${ }^{41}$ Likewise, the depolarisation signature of MC4R cells via closure of Kir7.1 has been defined in the slice preparation. ${ }^{32}$ Using this functional assay, we observed depolarisation of PVN MC4R neurones from Kcnj13+/+;MC4RCre mice in response to $\alpha-M S H$ (Figure 1A). By contrast, with the deletion of Kir7.1 in MC4R PVN neurones in Kcnj13 $\triangle M C 4 R^{C r e}$ mice, $\alpha-M S H$-induced depolarisation was no longer observed (Figure 1B), supporting the hypothesis that Kir7.1 is required for $\alpha-\mathrm{MSH}$-induced depolarisation of PVN MC4R neurones in the slice preparation. We have not surveyed this requirement for Kir7.1 in other MC4R neurones depolarised by $\alpha-\mathrm{MSH}$. Furthermore, we do not know how depolarisation of PVN MC4R neurones in the slice preparation correlates with the physiological sequelae of MC4R activation in vivo. Interestingly, although administration of MC4R agonists rapidly inhibits food intake (Figure 2 ), inhibition of food intake via optogenetic or chemogenetic activation of POMC neurones ${ }^{42,43}$ has a latency of several hours. Thus, it is possible that activation of 
MC4R neurones in a slice preparation reflects pharmacological but not necessarily physiological activation of the MC4R.

To investigate the role of Kir7.1 in mediating the pharmacological response to melanocortin agonist in vivo, we began by quantifying the feeding response on regular chow in response to an anorexigenic dose of exogenously administered $\alpha-\mathrm{MSH}$ analogue, LY2112688. No significant difference is observed in baseline daily chow consumption in control vs Kcnj13 $\triangle M C 4 R C r e$ mice (Figure 2A). Although food intake was potently inhibited by IP delivery of LY2112688 in animals with intact Kir7.1 in MC4R cells, male and female animals lacking Kir7.1 exhibited a reduced responsiveness to LY2112688 throughout the study, and also exhibited a greatly reduced duration of response. Specifically, animals lacking Kir7.1 in MC4R cells lost LY2112688 responsiveness typically by 12 hours, whereas control strains sustained responsiveness for 24-40 hours (Figure 2A-C). These results suggested that the sustained activity of an administered MC4R agonist requires Kir7.1. Experiments using viral knockdown of Kir7.1 in the PVN produced very similar findings, indicating that the effect was a result of the acute loss of function of Kir7.1 in PVN neurones, rather than a developmental defect.

This study parallels prior work using a $\mathrm{TI}^{+}$flux assay in HEK293 cells expressing MC4R and Kir7.1 to characterise the regulation of ion flux through Kir7.1 mediated by MC4R. ${ }^{44}$ These data suggested that the $G$ protein-mediated cAMP response peaks rapidly after $\alpha$ MSH exposure, whereas inhibition of Tl+ flux through Kir7.1 continued long after the CAMP response ebbed. ${ }^{32}$ Although our data clearly demonstrated pharmacological defects in response to melanocortin agonists in the absence of Kir7.1, it would also be interesting to examine the effects of chronic optogenetic stimulation of POMC neurones in the Kcnj13 $\triangle M C 4 R^{C r e}$ mouse, given the delayed anorexigenic response observed in this assay.

AgRP engages the MC4R at high affinity but does not couple the receptor to $G$ proteins or stimulate arrestin recruitment. ${ }^{45}$ Thus, when we determined that AgRP stimulates MC4R-dependent opening of Kir7.1, ${ }^{32}$ we predicted that AgRP was a biased agonist, signalling specifically via Kir7.1. We thus anticipated that the Kcnj13 $\Delta M C 4 R^{C r e}$ would have a reduced physiological response to the inverse agonist AgRP as well. However, a preliminary study demonstrated that i.c.v. delivery of AgRP to the hypothalamus induced similar hyperphagia and 4 days of weight gain in Kcnj13 $\Delta$ MC4RCre and control mice (see Supporting information, Figure S4). Thus, in contrast to our hypothesis, AgRP may not require Kir7.1 for normal signalling. Of course, these studies were also limited by virtue of being pharmacological in nature, and additional studies will need to be conducted to determine whether a compensatory signalling pathway has been activated in this knockout model, such as AgRP activation of ERK phosphorylation. ${ }^{46,47}$ Other explanations include the possibility that (i) AgRP functions exclusively as an inverse agonist and competitive antagonist of MC4R driven Gos signalling or (ii) AgRP also signals via an as yet unidentified mechanism. ${ }^{48-50}$

Not only is MC4R widely expressed in the CNS, but also sites of peripheral expression have been detected, namely in the peripheral nervous system and enteroendocrine L cells. ${ }^{36,37,51,52}$ Using an assay for detecting MC4R-dependent L-cell release of PYY in response to exogenous administration of the $\alpha-M S H$ analogue LY2112688, we found that the absence of Kir7.1 in MC4R cells has no effect on PYY release (Figure 3). These data clearly showed that MC4R induces PYY release in a Kir7.1-independent manner, emphasising that there are multiple modes of MC4R signalling, and that some physiological MC4R signalling events are Kir7.1-independent. Elevation of CAMP in $L$ cells has been demonstrated to stimulate PYY release. ${ }^{36}$

Deletion or haploinsufficiency of the MC4R results in a rapid onset of phenotypes, most prominently early onset obesity characterised by both hyperphagia, reduced energy expenditure and hyperinsulinaemia, observable by 8 weeks of age..$^{8,53,54}$ To address the physiological phenotype(s) of site-specific loss of Kir7.1 in MC4R cells, we investigated the weight gain profile, caloric consumption, body mass composition, linear growth and glucose metabolism of Kcnj13 $\triangle M C 4 R^{C r e}$ mice maintained on normal mouse chow. Initially, at the 9-15-week time points, we observed no change in body weight, body composition or metabolism in these mice. However, because mice were measured beyond 15 weeks, we observed that the $K c n j 13 \Delta M C 4 R^{C r e}$ mice tended to gain more weight than control genotypes, particularly in females. At 1 year of age, we observed increased weight in Kcnj13 $\triangle M C 4 R^{C r e}$ male and female mice compared to $\mathrm{Kcnj13}{ }^{\mathrm{fl} / f l}$, Kcnj13 ${ }^{+/+} ; M C 4 R^{\mathrm{Cre}}$ and $\mathrm{Kcnj13^{+/+ }} ; \mathrm{MC} \mathrm{R}^{+/+}$mice; moreover, female $K c n j 13 \Delta M C 4 R^{C r e}$ mice gained weight more rapidly than males (Figure 4A,B). It was interesting to note a large effect of Kir7.1 loss on linear growth at 30 weeks of age (Figure 4C-D), reminiscent of an effect seen on MC4R deletion. The late onset weight gain was clearly a result of increased adipose mass (Figure 4F) and not lean mass (Figure 4G), although it was not accompanied by any measurable hyperphagia (Figure 4E). The lean mass adjusted, low dose glucose tolerance test indicated deterioration of peripheral glucose metabolism in Kcnj13 $\triangle$ MC4RCre mice, associated with significant fat accrual (Figure 4J-L). MC4R signalling regulates glucose homeostasis in addition to excess adipose mass animals, both of which may have contributed to defective glucose utilisation shown here. ${ }^{7}$ It is possible that hyperphagia exists, although it is too small to be detected, in parallel with the very slow late onset obesity.

To potentially accelerate the effects of Kir7.1 deletion, we conducted similar experiments, placing mice on a HFD. Notably, the expression of MC4R-t2a-Cre-recombinase alone had an obesogenic effect on HFD fed mice (Figure 5A,C). Given the morbid early onset obesity arising from a 50\% reduction in MC4R expression in mice or humans, even a very small reduction of MC4R mRNA production, or a reduced production or function of the MC4R protein resulting from, for example, inefficient cleavage of the t2a site needed for release of Cre-recombinase from the MC4R-Cre fusion protein, could explain the obesity seen in $\mathrm{Kcnj} 13^{+/+} ; M C 4 R^{\mathrm{Cre}}$ mice fed high-fat chow. Similarly, it is possible that the 18-22 amino acid carboxy-terminal extension on the MC4R protein, resulting from cleavage of MC4R and Cre-recombinase, produced an MC4R with slightly reduced activity. However, these remain hypotheses because we have no data available regarding the MC4R mRNA or protein made by the MC4R-t2a-Cre-recombinase construct. 
Nonetheless, when Kir7.1 was ablated from MC4R cells, male and female mice were more sensitive to diet-induced weight gain than the Kcnj13+/+; MC4RCre controls (Figure 5A, C). This did not appear to be the result of a sustained measurable hyperphagic response (Figure 5B, D). A comparison of body mass composition by NMR reveals a significant increase in fat mass in both male and female $K c n j 13 \Delta M C 4 R^{C r e}$ animals compared to $K c n j 13+/+$ and $K c n j 13 \mathrm{fl} / \mathrm{fl}$ controls but not compared to Kcnj13+/+;MC4RCre (Figure 5E-H). Given the significant increase in total weight, we hypothesise that the lack of a difference in fat mass in $K c n j 13 \Delta M C 4 R^{C r e}$ animals vs controls may be the result of a lack of sensitivity of the whole animal NMR method.

After mice had matured on a HFD, a glucose tolerance test was conducted to test glucose utilisation. A low glucose dose $\left(1 \mathrm{mg} \mathrm{kg}^{-1}\right)$ adjusted to lean mass was used because mice on a HFD already have compromised glucose homeostasis. ${ }^{55}$ Here, the Cre-driver line had no intermediate phenotype, whereas the Kcnj13 $\Delta \mathrm{MC} 4 R^{\mathrm{Cre}}$ male and female mice had perturbed tolerance to glucose as confirmed by a significant increase in area under the curve (Figure $5 \mathrm{I}-\mathrm{L}$ ). The autonomic nervous system governs central glycaemia via its two arms: ChATMc4r expressing sympathetic neurones and Phox $2 b^{\mathrm{Mc} 4 \mathrm{r}}$ expressing parasympathetic neurones. ${ }^{53}$ Mice lacking MC4R present with hyperglycaemia and hyperinsulinaemia that is further exacerbated during fat accrual into maturity. Although parasympathetic nervous system outflow stimulates insulin release, sympathetic nervous system outflow via $\mathrm{ChAT}^{\mathrm{Mc} 4 \mathrm{r}}$ neurones has been demonstrated to modulate glycemic tone. ${ }^{17}$ The deteriorating weight maintenance and glucose intolerance in $K c n j 13 \Delta M C 4 R^{C r e}$ mice suggests that Kir7.1 may also augment MC4R signalling in autonomic nervous system pathways regulating glucose homeostasis.

The data reported in the present study show a measurable requirement for Kir7.1 in MC4R neurones for pharmacological responses to melanocortin agonists but not antagonists. In particular, Kir7.1 may be required for sustained responses to pharmacotherapy with melanocortin agonists such as setmelanotide. It will be informative to determine whether the delayed anorexigenic effect of optogenetic stimulation of POMC neurones requires Kir7.1. Likewise, given the apparent role of Kir7.1 in sustained anorexia, it may be informative to investigate the role of Kir7.1 in mediating the demonstrated role of MC4R signalling in disease cachexia in the mouse. ${ }^{56}$ Similarly, other physiological responses to melanocortins, such as those involved in the control of glucose homeostasis, may depend on Kir7.1.

We were surprised to note the very modest effect of Kir7.1 on body weight, as well as the divergence of the phenotype from that seen in MC4R knockout mice and patients with MC4R mutations. Indeed, all mutations leading to defective MC4R signalling, including mutations in MC4R, POMC, deletion of $\mathrm{G} \alpha \mathrm{S}$ in MC4R cells and even overexpression of AgRP, lead to a similar melanocortin obesity phenotype, characterised by early onset severe obesity, with hyperphagia, increased linear growth and increased lean mass. A very different phenotype, involving modest late onset obesity with no measurable hyperphagia, increased linear growth and no increase in lean mass, was instead observed in mice lacking Kir7.1 in MC4R cells. There are many potential explanations for these findings, including changes that compensate early on for the absence of Kir7.1. Recently, a rather dramatic example was reported illustrating the tremendous compensatory plasticity of the melanocortin circuits in response to early developmental gene knockout. ${ }^{57}$ Deletion of leptin receptor from AgRP neurones is found to produce only a minor obesity and diabetes phenotype, ${ }^{58}$ relative to global leptin receptor deletion. By contrast, CRISPR-mediated deletion of the gene in AgRP neurones in adult animals produced a morbid obesity syndrome almost paralleling that seen in the $d b / d b$ mouse. ${ }^{57}$ Even more relevant to the present study, leptin hyperpolarises neurones by opening the $\mathrm{K}_{\text {ATP }}$ channel. ${ }^{59}$ Although global deletion of the Kir6.2 subunit of this channel had a limited effect on glucose homeostasis and no obesogenic effect, ${ }^{60,61}$ CRISPR-mediated mutagenesis of Kir6.2 in AgRP neurones alone yielded a morbid obesity syndrome with diabetes. ${ }^{57}$ Thus, it is possible that a wholly different phenotype may be seen upon deletion of Kir7.1 in the adult mouse.

Alternatively, the results reported in the present study may indicate that Kir7.1 plays a very specific and limited role in the physiological functioning of the MC4R. Additionally, the data obtained do not rule out the possibility that the phenotype results from a minor developmental alteration in a subset of MC4R neurones. Furthermore, we provide a direct example of a physiologically-mediated MC4R pathway, PYY release, from L cells, which appears to be Kir7.1-independent. Interestingly, irrespective of the physiological role(s) for Kir7.1 in MC4R signalling, the present study demonstrates a significant pharmacological effect of Kir7.1 in vivo and in the slice preparation. These data may thus be important for the ongoing challenge with respect to the development of therapeutics acting at the MC4R, further highlighting the complexities of MC4R signalling that remain to be solved.

\section{ACKNOWLEDGEMENTS}

This study was supported by NIH RO1 DK070332 (RDC), NIH RO1 DK110403 (GLM), METP training grant NIH T32 DK07563 (EJPA), F30DK108476 (MJL) and Pfizer, Inc. (RDC). We thank Savannah Y. Williams and Heidi Moreno for their excellent technical assistance; Rachel Chandler and Stephanie King for assistance with figures; and Hakmook Kang for biostatistical analyses. We also thank Bradford Lowell for providing the Mc4r-2A-Cre Tg/+ line (Jax Stock No. 030759). The ES cells used for this research project were generated by the trans-NIH Knock-Out Mouse Project (KOMP) and obtained from the KOMP Repository (www.komp.org). NIH grants to Velocigene at Regeneron Inc. (U01HG004085) and the CSD Consortium (U01HG004080) funded the generation of gene-targeted ES cells for 8500 genes in the KOMP Program and archived and distributed by the KOMP Repository at UC Davis and CHORI (U42RR024244). More information about KOMP is available at: www.komp.org.

\section{ORCID}

Roger D. Cone (iD https://orcid.org/0000-0003-3333-5651 


\section{REFERENCES}

1. Vaisse C, Clement K, Guy-Grand B, Froguel P. A frameshift mutation in human MC4R is associated with a dominant form of obesity. Nat Genet. 1998;20:113-114.

2. Yeo GS, Farooqi IS, Aminian S, Halsall DJ, Stanhope RG, O'Rahilly S. A frameshift mutation in MC4R associated with dominantly inherited human obesity. Nat Genet. 1998;20:111-112.

3. Alharbi KK, Spanakis E, Tan K, et al. Prevalence and functionality of paucimorphic and private MC4R mutations in a large, unselected European British population, scanned by meltMADGE. Hum Mutat. 2007; 28:294-302.

4. Farooqi IS, Keogh JM, Yeo GS, Lank EJ, Cheetham T, O'Rahilly S. Clinical spectrum of obesity and mutations in the melanocortin 4 receptor gene. N Engl J Med. 2003;348:1085-1095.

5. Branson R, Potoczna N, Kral JG, Lentes KU, Hoehe MR, Horber FF. Binge eating as a major phenotype of melanocortin 4 receptor gene mutations. N Engl J Med. 2003;348:1096-1103.

6. Butler AA, Cone RD. Knockout models resulting in the development of obesity. Trends Genet. 2001;17:S50-S54.

7. Fan W, Dinulescu DM, Butler AA, Zhou J, Marks DL, Cone RD. The central melanocortin system can directly regulate serum insulin levels. Endocrinology. 2000;141:3072-3079.

8. Huszar D, Lynch CA, Fairchild-Huntress V, et al. Targeted disruption of the melanocortin-4 receptor results in obesity in mice. Cell. 1997;88:131-141.

9. Qi L, Kraft P, Hunter DJ, Hu FB. The common obesity variant near MC4R gene is associated with higher intakes of total energy and dietary fat, weight change and diabetes risk in women. Hum Mol Genet. 2008;17:3502-3508.

10. Loos RJ, Lindgren CM, Li S, et al. Common variants near MC4R are associated with fat mass, weight and risk of obesity. Nat Genet. 2008;40:768-775.

11. Chambers JC, Elliott $P$, Zabaneh $D$, et al. Common genetic variation near MC4R is associated with waist circumference and insulin resistance. Nat Genet. 2008;40:716-718.

12. Fan W, Boston BA, Kesterson RA, Hruby VJ, Cone RD. Role of melanocortinergic neurons in feeding and the agouti obesity syndrome. Nature. 1997;385:165-168.

13. Marks D, Cone RD. The role of the melanocortin-3 receptor in cachexia. Ann N Y Acad Sci. 2003;994:258-266.

14. Marks DL, Ling N, Cone RD. Role of the central melanocortin system in cachexia. Cancer Res. 2001;61:1432-1438.

15. Cheung WW, Kuo HJ, Markison S, et al. Peripheral administration of the melanocortin-4 receptor antagonist NBI-12i ameliorates uremia-associated cachexia in mice. J Am Soc Nephrol. 2007;18:2517-2524.

16. Cheung WW, Mak RH. Melanocortin antagonism ameliorates muscle wasting and inflammation in chronic kidney disease. Am J Physiol Renal Physiol. 2012;303:F1315-F1324.

17. Rossi J, Balthasar N, Olson D, et al. Melanocortin-4 receptors expressed by cholinergic neurons regulate energy balance and glucose homeostasis. Cell Metab 2100;13:195-204.

18. Zechner JF, Mirshahi UL, Satapati S, et al. Weight-independent effects of roux-en-Y gastric bypass on glucose homeostasis via melanocortin-4 receptors in mice and humans. Gastroenterology. 2013;144:580-590.

19. Itoh M, Suganami T, Nakagawa N, et al. Melanocortin 4 receptordeficient mice as a novel mouse model of nonalcoholic steatohepatitis. Am J Pathol. 2011;179:2454-2463.

20. Perez-Tilve D, Gonzalez-Matias L, Aulinger BA, et al. Exendin-4 increases blood glucose levels acutely in rats by activation of the sympathetic nervous system. Am J Physiol Endocrinol Metab. 2010;298:E1088-E1096.
21. Lim BK, Huang KW, Grueter BA, Rothwell PE, Malenka RC. Anhedonia requires MC4R-mediated synaptic adaptations in nucleus accumbens. Nature. 2012;487:183-189.

22. Xu P, Grueter BA, Britt JK, et al. Double deletion of melanocortin 4 receptors and SAPAP3 corrects compulsive behavior and obesity in mice. Proc Natl Acad Sci USA. 2013;110:10759-10764.

23. Cowley MA, Pronchuk N, Fan W, Dinulescu DM, Colmers WF, Cone RD. Integration of NPY, AGRP, and melanocortin signals in the hypothalamic paraventricular nucleus: evidence of a cellular basis for the adipostat. Neuron. 1999;24:155-163.

24. Kievit P, Halem H, Marks DL, et al. Chronic treatment with a melanocortin-4 receptor agonist causes weight loss, reduces insulin resistance, and improves cardiovascular function in diet-induced obese rhesus macaques. Diabetes. 2012;62:490-497.

25. Chen KY, Muniyappa R, Abel BS, et al. RM-493, a melanocortin-4 receptor (MC4R) agonist, increases resting energy expenditure in obese individuals. J Clin Endocrinol Metabol. 2015;100:1639-1645.

26. Fosgerau K, Raun K, Nilsson C, Dahl K, Wulff BS. Novel alpha-MSH analog causes weight loss in obese rats and minipigs and improves insulin sensitivity. J Endocrinol. 2014;220:97-107.

27. Collet TH, Dubern B, Mokrosinski J, et al. Evaluation of a melanocortin-4 receptor (MC4R) agonist (Setmelanotide) in MC4R deficiency. Mol Metab. 2017;6:1321-1329.

28. Clement K, Biebermann H, Farooqi IS, et al. MC4R agonism promotes durable weight loss in patients with leptin receptor deficiency. Nat Med. 2018;24:551-555.

29. Podyma B, Sun $H$, Wilson EA, et al. The stimulatory $G$ protein Gsalpha is required in melanocortin 4 receptor-expressing cells for normal energy balance, thermogenesis and glucose metabolism. J Biol Chem. 2018;293:10993-11005.

30. Sohn JW, Harris LE, Berglund ED, et al. Melanocortin 4 receptors reciprocally regulate sympathetic and parasympathetic preganglionic neurons. Cell. 2013;152:612-619.

31. Sohn JW, Elmquist JK, Williams KW. Neuronal circuits that regulate feeding behavior and metabolism. Trends Neurosci. 2013;36:504-512.

32. Ghamari-Langroudi M, Digby GJ, Sebag JA, et al. G-protein-independent coupling of MC4R to Kir7.1 in hypothalamic neurons. Nature 2015;520:94-98.

33. Liu H, Kishi T, Roseberry AG, et al. Transgenic mice expressing green fluorescent protein under the control of the melanocortin-4 receptor promoter. J Neurosci. 2003;23:7143-7154.

34. Ayala JE, Bracy DP, James FD, Burmeister MA, Wasserman DH, Drucker DJ. Glucagon-like peptide-1 receptor knockout mice are protected from high-fat diet-induced insulin resistance. Endocrinology. 2010;151:4678-4687.

35. Villanueva S, Burgos J, Lopez-Cayuqueo KI, et al. Cleft palate, moderate lung developmental retardation and early postnatal lethality in mice deficient in the Kir7.1 inwardly rectifying K+ channel. PLoS ONE 2015;10:e0139284.

36. Panaro BL, Tough IR, Engelstoft MS, et al. The melanocortin-4 receptor is expressed in enteroendocrine $L$ cells and regulates the release of peptide YY and glucagon-like peptide 1 in vivo. Cell Metab. 2014;20:1018-1029.

37. Tao YX. The melanocortin-4 receptor: physiology, pharmacology, and pathophysiology. Endocr Rev. 2010;31:506-543.

38. Pattnaik BR, Shahi PK, Marino MJ, et al. A novel KCNJ13 nonsense mutation and loss of Kir7.1 channel function causes leber congenital amaurosis (LCA16). Hum Mutat 2015;36:720-727.

39. Pattnaik BR, Tokarz S, Asuma MP, et al. Snowflake vitreoretinal degeneration (SVD) mutation $\mathrm{R} 162 \mathrm{~W}$ provides new insights into Kir7.1 ion channel structure and function. PLoS ONE 2013;8:e71744. 
40. Iwashita M, Watanabe M, Ishii M, et al. Pigment pattern in jaguar/ obelix zebrafish is caused by a Kir7.1 mutation: implications for the regulation of melanosome movement. PLoS Genet 2006;2:e197.

41. Ghamari-Langroudi M. Electrophysiological analysis of circuits controlling energy homeostasis. Mol Neurobiol. 2012;45:258-278.

42. Aponte $\mathrm{Y}$, Atasoy D, Sternson SM. AGRP neurons are sufficient to orchestrate feeding behavior rapidly and without training. Nat Neurosci. 2011;14:351-355.

43. Zhan C, Zhou J, Feng Q, et al. Acute and long-term suppression of feeding behavior by POMC neurons in the brainstem and hypothalamus, respectively. J Neurosci. 2013;33:3624-3632.

44. Litt MJ, Cone RD, Ghamari-Langroudi M. Characterization of MC4R Regulation of the Kir7.1 Channel Using the TI(+) Flux Assay. Methods Mol Biol 2018;1684:211-222.

45. Breit A, Wolff K, Kalwa H, Jarry H, Buch T, Gudermann T. The natural inverse agonist agouti-related protein induces arrestin-mediated endocytosis of melanocortin-3 and -4 receptors. J Biol Chem. 2006;281:37447-37456.

46. Mo XL, Tao YX. Activation of MAPK by inverse agonists in six naturally occurring constitutively active mutant human melanocortin-4 receptors. Biochem Biophys Acta. 2013;1832:1939-1948.

47. Tao YX. Constitutive activity in melanocortin-4 receptor: biased signaling of inverse agonists. Adv Pharmacol. 2014;70:135-154.

48. Gropp E, Shanabrough M, Borok E, et al. Agouti-related peptide-expressing neurons are mandatory for feeding. Nat Neurosci. 2005;8:289-291.

49. Luquet S, Perez FA, Hnasko TS, Palmiter RD. NPY/AgRP neurons are essential for feeding in adult mice but can be ablated in neonates. Science. 2005;310:683-685.

50. Wu Q, Howell MP, Cowley MA, Palmiter RD. Starvation after AgRP neuron ablation is independent of melanocortin signaling. Proc Natl Acad Sci USA. 2008;105:2687-2692.

51. Mountjoy KG, Jenny Wu CS, Dumont LM, Wild JM. Melanocortin-4 receptor messenger ribonucleic acid expression in rat cardiorespiratory, musculoskeletal, and integumentary systems. Endocrinology. 2003;144:5488-5496.

52. Mountjoy KG, Mortrud MT, Low MJ, Simerly RB, Cone RD. Localization of the melanocortin-4 receptor (MC4-R) in neuroendocrine and autonomic control circuits in the brain. Mol Endocrinol. 1994;8:1298-1308.

53. Krashes MJ, Lowell BB, Garfield AS. Melanocortin-4 receptor-regulated energy homeostasis. Nat Neurosci. 2016;19:206-219.
54. Garfield AS, Li C, Madara JC, et al. A neural basis for melanocortin-4 receptor-regulated appetite. Nat Neurosci. 2015;18:863-871.

55. McGuinness OP, Ayala JE, Laughlin MR, Wasserman DH. NIH experiment in centralized mouse phenotyping: the Vanderbilt experience and recommendations for evaluating glucose homeostasis in the mouse. Am J Physiol Endocrinol Metab. 2009;297:E849-E855.

56. Marks DL, Ling N, Cone RD. Role of the central melanocortin system in cachexia. Cancer Res. 2001;61:1432-1438.

57. $\mathrm{Xu} \mathrm{J,} \mathrm{Bartolome} \mathrm{CL,} \mathrm{Low} \mathrm{CS,} \mathrm{et} \mathrm{al.} \mathrm{Genetic} \mathrm{identification} \mathrm{of}$ leptin neural circuits in energy and glucose homeostases. Nature. 2018;556:505-509.

58. van de Wall E, Leshan $R, X u A W$, et al. Collective and individual functions of leptin receptor modulated neurons controlling metabolism and ingestion. Endocrinology. 2008;149:1773-1785.

59. Spanswick D, Smith MA, Groppi VE, Logan SD, Ashford ML. Leptin inhibits hypothalamic neurons by activation of ATP-sensitive potassium channels. Nature. 1997;390:521-525.

60. Miki T, Nagashima K, Tashiro F, et al. Defective insulin secretion and enhanced insulin action in KATP channel-deficient mice. Proc Natl Acad Sci USA. 1998;95:10402-10406.

61. Seghers V, Nakazaki M, DeMayo F, Aguilar-Bryan L, Bryan J. Sur1 knockout mice. A model for K(ATP) channel-independent regulation of insulin secretion. J Biol Chem 2000;275:9270-9277.

\section{SUPPORTING INFORMATION}

Additional supporting information may be found online in the Supporting Information section at the end of the article.

How to cite this article: Anderson EJP, Ghamari-Langroudi

$\mathrm{M}$, Cakir I, et al. Late onset obesity in mice with targeted deletion of potassium inward rectifier Kir7.1 from cells expressing the melanocortin-4 receptor. J Neuroendocrinol. 2019;31:e12670. https://doi.org/10.1111/jne.12670 